\title{
Does body size affect fitness the same way in males and females? A test of multiple fitness components
}

\author{
Ashlee N. Smith \\ Brigham Young University - Provo \\ Mark C. Belk \\ Brigham Young University - Provo, mark_belk@byu.edu
}

Follow this and additional works at: https://scholarsarchive.byu.edu/facpub

Part of the Biology Commons

\section{Original Publication Citation}

Smith AN, MC Belk. 2018. Does body size affect fitness the same way in males and females? A test of multiple fitness components. Biological Journal of the Linnean Society 124:47-55.

\section{BYU ScholarsArchive Citation}

Smith, Ashlee N. and Belk, Mark C., "Does body size affect fitness the same way in males and females? A test of multiple fitness components" (2018). Faculty Publications. 5420.

https://scholarsarchive. byu.edu/facpub/5420

This Peer-Reviewed Article is brought to you for free and open access by BYU ScholarsArchive. It has been accepted for inclusion in Faculty Publications by an authorized administrator of BYU ScholarsArchive. For more information, please contact ellen_amatangelo@byu.edu. 


\title{
Does body size affect fitness the same way in males and females? A test of multiple fitness components
}

\author{
ASHLEE N. SMITH* and MARK C. BELK \\ Biology Department, Brigham Young University, Provo, UT 84602, USA \\ Received 13 December 2017; revised 16 February 2018; accepted for publication 16 February 2018
}

\begin{abstract}
Body size generally has an important relationship with fitness, whereby larger body size leads to an increase in fitness through competition, reproductive output and survivorship. However, the traits through which body size increases fitness often differ between the sexes. We tested for the effects of body size on fitness in both sexes using three separate experiments on competitive ability, reproductive output and starvation resistance in the burying beetle Nicrophorus marginatus. Results varied between sexes as follows: (1) larger body size increased competitive ability differentially between sexes; (2) female body size, but not male body size, significantly affected reproductive output (small females produced larger broods of smaller offspring, whereas large females produced smaller broods of larger offspring); and (3) large body size was positively associated with starvation resistance, but there was no differential response by sex. This study indicates that there is a complex relationship between body size, sex and fitness, and that multiple fitness parameters need to be tested in both sexes to understand the evolution and importance of body size in a species.
\end{abstract}

ADDITIONAL KEYWORDS: body size - burying beetle - competition - evolution - Nicrophorus marginatus reproductive output - starvation resistance.

\section{INTRODUCTION}

Body size of organisms is one of the most widely studied physical traits because of its influence on many behavioural, physiological and life-history traits (Roff, 1992). However, the diversity of pathways through which body size can affect fitness has been of particular interest. Fitness tends to increase with body size through sexual selection, an increase in reproductive success, increased viability, predator avoidance and starvation resistance (Clutton-Brock, 1988; Blanckenhorn, 2000). Most studies have addressed only one pathway through which body size affects fitness (but for exceptions, see: Amarillo-Suárez, Stillwell \& Fox, 2011; Hsu \& Soong, 2017), but single-pathway studies cannot address the probably multivariate effect of body size on fitness.

Although there is a well-documented relationship between large body size and fitness, the degree and direction of this relationship often differ between males and females (Fairbairn, Blanckenhor \& Székely, 2007). Body size generally affects male fitness through

*Corresponding author. E-mail: ashleens@byu.edu male-male competition and sexual selection because females are usually the limiting sex, and therefore males must compete for access to females (Emlen \& Oring, 1977; Clutton-Brock, 1983). However, reproductive output is more likely to vary with female body size through increased fecundity with larger body size (Emlen \& Oring, 1977). Tests of sex-specific differences in survival have been mixed (e.g. Badyaev et al., 2002; Råberg, Stjernman \& Nilsson, 2005; Husby et al., 2006; Altwegg, Schaub \& Roulin, 2007; Cleasby et al., 2010). Comprehensive tests on the importance of body size for multiple factors in both sexes are needed to understand the complex interactions that lead to the evolution of body size in males and females (Blanckenhorn, 2005).

In this study, we use the burying beetle Nicrophorus marginatus to test for the effect of body size on fitness in both sexes. Body size is closely linked to fitness through several aspects of burying beetle natural history, including the following: (1) flight to locate carcasses for reproduction (larger beetles are able to fly at a broader range of temperatures; Merrick \& Smith, 2004); (2) competitions for carcasses for reproduction (larger beetles are more likely to win competitions 
for carcasses in both intra- and interspecific contests; Otronen, 1988; Eggert \& Sakaluk, 2000); (3) parental care (after winning access to a carcass, body size can affect the duration and extent of parental care; Steiger, 2013; Smith, Belk \& Creighton, 2014; Pilakouta, Richardson \& Smiseth, 2015); (4) reproductive output (body size has been linked to variation in brood size in both sexes; Rauter et al., 2010; Hopwood et al., 2016); and (5) survival (body size has been shown to affect overwinter survival and starvation resistance; Smith, 2002; Trumbo \& Xhihani, 2015). Thus, there are several different ways in which body size can affect fitness in burying beetles, but some of these factors might act differently in males and females.

The goal of this study was to determine whether body size is equally important for multiple aspects of fitness in both sexes in $N$. marginatus. Body size is likely to affect both males and females through competitions for carcasses, reproductive output and starvation resistance in this species. We tested for these effects through three separate experiments that used: (1) competitive trials between beetles of various sizes; (2) tests of reproductive output of large and small beetles on large and small carcasses; and (3) tests of the time to death in starvation conditions for a range of body sizes. For each of these traits, the sexes could be affected equally, differently or not at all. We predicted that body size would be equally important for males and females for all three of these traits owing to their similar natural histories and their engagement in biparental care. However, our results show a range of responses to these factors, indicating a complex relationship between body size and fitness between sexes in this species.

\section{MATERIAL AND METHODS}

\section{SOURCE OF BURYING BEETLES}

Adult $N$. marginatus used to generate the laboratory population were captured at the Utah Wetland Preserve near Goshen, Utah in August 2014, July 2015 and July 2016 using pitfall traps baited with aged chicken. Wild-caught pairs were placed on $40 \mathrm{~g}$ mouse carcasses and allowed to breed to generate the laboratory population. We created 41, 55 and 33 independent genetic lines from wild-caught pairs in 2014, 2015 and 2016 , respectively. The date of eclosion was designated as the first day of adult life for all laboratory-bred beetles. Individuals were placed in small plastic containers $(15.6 \mathrm{~cm} \times 11.6 \mathrm{~cm} \times 6.7 \mathrm{~cm})$, fed ad libitum raw chicken liver twice weekly, and maintained on a $14 \mathrm{~h}-10 \mathrm{~h}$ light-dark cycle at $21^{\circ} \mathrm{C}$ until they were used in experiments.

\section{EXPERIMENTAL DESIGN}

\section{Competition experiment}

The purpose of this experiment was to determine the effect of body size (for both sexes) on the outcome of competitions for carcasses. We began each trial by randomly choosing two beetles of the same sex that were not genetically related. We then determined the difference in their body sizes by measuring their pronotum widths (replicated three times) using digital callipers. We used pronotum width rather than mass because it is a better predictor of the outcome of fights in Nicrophorus (Safryn \& Scott, 2000). Each pair was then assigned to a size difference category as follows: $1=0-0.1 \mathrm{~mm}$ difference; $2=0.11-0.2 \mathrm{~mm}$ difference; $3=0.21-0.3 \mathrm{~mm}$ difference $4=0.31-0.4 \mathrm{~mm}$ difference; and $5=0.41-0.5 \mathrm{~mm}$ difference. We randomly chose one beetle from the competing pair to be marked with a small dot of white paper corrector fluid on one of its elytra for identification. (Marking a beetle did not have a negative effect the outcome of the competition. In males, the marked beetle won $56 \%$ of competitions, and in females the marked beetle won $47 \%$ of competitions.) The pair was then placed in a large plastic container $(88.5 \mathrm{~cm} \times 42 \mathrm{~cm} \times 15.5 \mathrm{~cm})$ with a mouse carcass weighing $27-33 \mathrm{~g}$. The two beetles were initially placed in opposite corners of the container. We then observed the pair for $30 \mathrm{~min}$ and noted any interactions between the beetles to determine whether the more aggressive beetle was the ultimate winner of the contest. The more aggressive beetle won access to the carcass only $\sim 50 \%$ of the time, so we did not analyse the aggressive interactions further. After $30 \mathrm{~min}$ of observation, the lid was placed on the container and the pair was left overnight. The following day, we checked the container and determined the winner of the competition as the individual in possession of the carcass. We completed 100 competition trials for each sex, 20 in each of the five size categories for both sexes, which gave us a total of 200 trials. In two trials, one in size category 1 and one in size category 4 , both females were found on the carcass after $24 \mathrm{~h}$, so those trials were excluded from the analyses.

\section{Reproduction experiment}

The purpose of this experiment was to determine how body size and carcass size affect reproductive output. We measured three response variables: final brood size; mean individual offspring mass; and total brood mass. We addressed this question by allowing large and small beetles to reproduce on large or small carcasses. We used the pronotum widths of beetles collected in the field in 2014 to determine the mean size for each sex, and sizes that were between one and two standard deviations (SDs) above and below the 
mean were considered large and small, respectively. The mean pronotum width of females was $6.67 \mathrm{~mm}$, with an SD of $0.78 \mathrm{~mm}(N=50)$. The mean pronotum width of males was $6.87 \mathrm{~mm}$, with an SD of $0.72 \mathrm{~mm}$ $(N=50)$. Therefore, the size range of large and small female beetles used in this experiment was 7.44-8.22 and 5.11-5.89 mm, respectively. The size range of large and small male beetles was 7.60-8.32 and 5.42$6.15 \mathrm{~mm}$, respectively. This experiment represented a fully crossed factorial design. There were four size treatments: large male with large female; large male with small female; small male with large female; and small male with small female. Each size treatment was crossed with both small (20 g) and large (40 g) carcasses, for a total of eight treatment combinations. Twelve replicates were completed for each of the eight treatments. One replicate (large male, small female, $20 \mathrm{~g}$ carcass) yielded no offspring, so it was excluded from the statistical analyses.

We began each trial by choosing a genetically unrelated pair of beetles that fitted into one of the size treatments. We recorded the initial mass and pronotum width of each beetle. The pair was placed in a small brood container $(16.5 \mathrm{~cm} \times 15 \mathrm{~cm} \times 9 \mathrm{~cm})$ filled with $6 \mathrm{~cm}$ of moist soil and given either a $20 \mathrm{~g} \mathrm{(} \pm$ $1.0 \mathrm{~g})$ or a $40 \mathrm{~g}( \pm 2.0 \mathrm{~g})$ mouse carcass. The containers were kept in an environmental chamber at $21^{\circ} \mathrm{C}$ on a $14 \mathrm{~h}-10 \mathrm{~h}$ light-dark cycle. The brood containers were checked daily, and after larvae arrived on the carcass, the lid of the small brood container was removed and the container was placed in an abandonment chamber $(37.5 \mathrm{~cm} \times 25.5 \mathrm{~cm} \times 14.5 \mathrm{~cm}$; see Smith et al., 2014 for details). We used the abandonment chambers to create a more natural experimental design that allowed the parents to remain with the brood or abandon it as they normally would, but we did not analyse any of the parental abandonment data.

Abandonment chambers were checked daily, and the number of larvae was recorded every day, but we used only the number of eclosed offspring in our analysis. We counted the larvae by carefully removing each larva from the carcass with forceps. The larvae were returned to the carcass immediately after they were counted. The cups in each corner of the abandonment chambers were also checked daily to see whether an adult had abandoned the brood. If a parent was found in a cup, its mass and the date were recorded, and it was placed back in the small container with the brood. If a parent abandoned the brood for a second time, it was removed. When the larvae dispersed into the soil, the remaining parent(s) were removed and weighed. The larvae from each brood reached eclosion 4-5 weeks after dispersal. The number of newly eclosed adult offspring was used to determine the total number of offspring. Each newly eclosed adult offspring was weighed, and we used these data to calculate the mean individual offspring mass and total offspring mass produced.

\section{Starvation resistance experiment}

The purpose of this experiment was to determine the effect of body size on starvation resistance. We began this experiment by placing 20 sexually mature $N$. marginatus pairs on $40 \mathrm{~g}( \pm 2.0 \mathrm{~g})$ carcasses and allowing them to reproduce. When larvae dispersed, the mass of each individual larva was recorded, and three larvae from each brood (the heaviest, the lightest and one from the middle of the range) were placed individually in small containers with moist soil. The larvae were allowed to complete development, and their mass, sex, pronotum width and date of eclosion were recorded. The eclosed offspring were not given any food and were checked daily to determine when they died. Four beetles, one small, one medium and two large, did not develop and died in the pupal stage, which gave us a total of 56 replicates ( 24 females and 32 males) for this experiment.

\section{STATISTICAL ANALYSES}

\section{Competition experiment}

To test for the probability of winning a carcass, we used a generalized linear model with a logit link function and assumed a binomial distribution of the response variable (Proc GENMOD in SAS; SAS 9.3; SAS Institute, Cary, NC, USA). The data did not exhibit overdispersion (Harrison, 2015). We modelled the probability that the smaller beetle would win a competitive interaction. The response variable was either success (coded as one) or failure (coded as zero) of the smaller beetle to win the competitive bout. Predictor variables were the size difference (five levels) and sex (two levels), and we included the interaction between size and sex. The model also included the pronotum width of the smaller beetle as a covariate to determine whether absolute size influenced the competitive outcome.

\section{Reproduction experiment}

To determine effects of body size on reproductive output, we used three response variables: final brood size (the number of eclosed adult offspring); total offspring mass; and individual offspring mass. In the competition experiment and in the starvation resistance experiment, we used pronotum width as our measure of body size. In the reproduction experiment, we used pronotum width as our measure of body size for the parents, but we used mass of offspring as our measure of the response. We felt that mass of offspring better reflected the energetic investment in offspring, and there is a strong correlation between body mass and 
pronotum width $\left(R^{2}=0.92\right)$, so they are interchangeable as response variables for this analysis. For brood size, we used a generalized linear model with a log-link function and assumed a Poisson distribution of the response variable (the data did not exhibit overdispersion; Harrison, 2014; Proc GENMOD in SAS; SAS 9.3). For total offspring mass and mean offspring size, we used a general linear model to determine the effect of parental size and carcass size on reproductive output (Proc GLM in SAS; SAS 9.3). For analysis of each response variable, we used the same set of predictor variables: female parent body size (two levels); male parent body size (two levels); and carcass size (two levels). The model also included all two-way and threeway interactions. We evaluated total offspring mass and individual offspring mass for normality of residuals and equal variances across treatment combinations by inspecting the distribution of residuals and studentized residuals vs. predicted values. Untransformed data met these assumptions for these two response variables. For brood size, the log-link function satisfied the assumptions of normality of residuals and equal variances across treatment combinations. For each of the response variables, we tested the full model that included all interactions. Interactions were not significant for any of the three models. We removed all interaction terms and compared the Akaike information criterion score from the model that had only main effects with the full model. The reduced model exhibited a better fit in all three cases; therefore, we report results from the reduced model.

\section{Starvation resistance experiment}

We used a generalized linear model and assumed a Poisson distribution of the response variable (the data exhibited no overdispersion; Harrison, 2014). The response variable was the number of days to starvation, and the predictor variables were pronotum width, sex and their interaction. We also included the parental pair number as a random effect to control for family effects. We used the glmer function and the blmeco package (Korner-Nievergelt et al., 2015) in R 3.3.3 (R Core Team, 2013) for this analysis.

\section{RESULTS}

\section{COMPETITION EXPERIMENT}

Sex and the size difference between beetles significantly affected the probability of the smaller beetle winning a competitive interaction, but the pronotum width of the smaller competitor and the interaction between sex and size difference did not have significant effects on the outcome of competitions (Table 1). In males, the probability of the smaller beetle winning the competition decreased from 39\% (not statistically different from 50\%) in the smallest size difference category to $0 \%$ in the largest size difference category (Fig. 1). In females, however, the probability of the smaller beetle winning the competition decreased from $42 \%$ (not statistically different from $50 \%$ ) in the smallest size difference category to only $20 \%$ in the largest size difference category (Fig. 1). Overall, smaller males are $17 \%$ less likely to win in competitions than are smaller females across the entire range of size differences tested.

\section{REPRODUCTION EXPERIMENT}

Parents produced significantly more offspring on $40 \mathrm{~g}$ carcasses than on $20 \mathrm{~g}$ carcasses, and female size had a moderately significant effect on final brood size, but male size did not significantly affect final brood size (Table 2 ). Females produced $\sim 42 \%$ more offspring (about five individuals) on $40 \mathrm{~g}$ carcasses compared with 20 g carcasses. Small females produced $\sim 14 \%$ more offspring (two individuals) in a brood than large females across both carcass sizes (Fig. 2A).

There were significant differences in the mean individual offspring mass between carcass sizes, and the mass of the female parent had a significant effect, but male size did not (Table 2). Parents produced individual offspring that were $19 \%$ heavier on $40 \mathrm{~g}$ carcasses compared with $20 \mathrm{~g}$ carcasses. Large females produced individual offspring that were $\sim 8 \%$ heavier than those produced by small females (Fig. $2 \mathrm{~B}$ ).

There were significant differences in total offspring mass of a brood between carcass sizes, but male size and female size did not have a significant effect (Table 2).

Table 1. Competition experiment analysis table for the effects of size difference, sex, the interaction between sex and size difference, and the pronotum width of the smaller competitor on the outcome of a competitive interaction

\begin{tabular}{|c|c|c|c|c|}
\hline Response variable & Source & Numerator d.f./Denominator d.f. & $F$-value & $P$-value \\
\hline \multirow[t]{4}{*}{ Small beetle wins (1) or loses (0) } & Size difference & $4 / 177$ & 4.38 & $0.002^{*}$ \\
\hline & Sex & $1 / 177$ & 8.96 & $0.003^{*}$ \\
\hline & Sex $\times$ size difference & $4 / 177$ & 1.26 & 0.29 \\
\hline & Small beetle pronotum width & $1 / 177$ & 0.53 & 0.47 \\
\hline
\end{tabular}

*Significant values. 
Parents produced broods that were $\sim 43 \%$ heavier on $40 \mathrm{~g}$ carcasses compared with $20 \mathrm{~g}$ carcasses (Fig. 2C).

\section{STARVATION RESISTANCE EXPERIMENT}

There were significant differences in starvation resistance according to pronotum width, but sex and the interaction between pronotum width and sex were not significant (Table 3). On average, the largest beetles of both sexes lived $\sim 13$ days without food, whereas the smallest beetles of both sexes lived $\sim 2$ days without food (Fig. 3).

\section{DISCUSSION}

The results of the experiments in this study indicate that the pathways through which body size affects fitness differ between the sexes. In $N$. marginatus, large body size is important for fitness through competitions

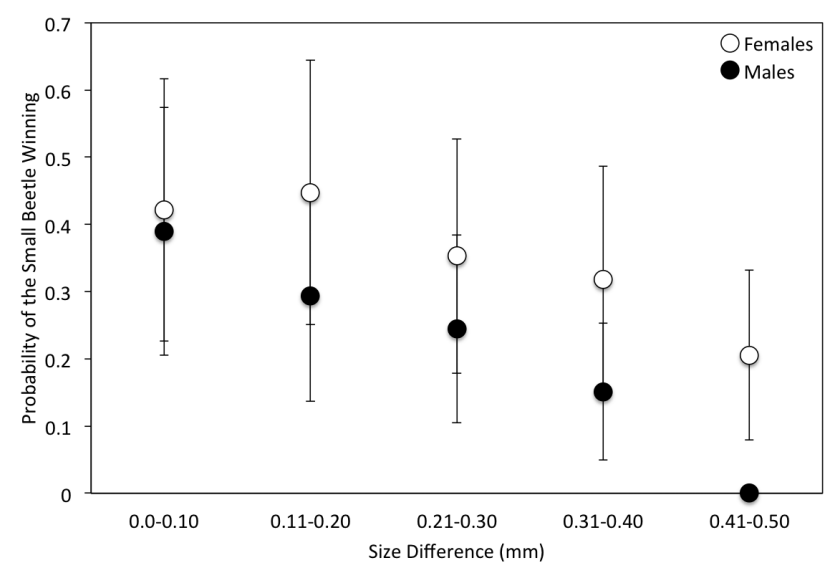

Figure 1. Least squares means $( \pm 95 \%$ confidence interval) for the probability of the smaller beetle winning a competition according to size difference category and sex. for carcasses in both sexes, but body size seems to be more important for males than for females. In contrast, female body size is related to the individual mass of offspring and number of offspring produced, whereas male body size is not related to reproductive output. Finally, large body size affects starvation resistance in both sexes. These results are consistent with previous research showing that male body size is important in intrasexual competitions (Emlen \& Oring, 1977; Clutton-Brock, 1983), but female body size affects reproductive output (Emlen \& Oring, 1977). The unique natural history of burying beetles is likely to influence the similarities and differences through which body size affects fitness in each sex, which we discuss below.

Larger individuals of both sexes have more success at winning access to carcasses (Fig. 1). However, in competitions between males the larger individual is more likely to win compared with competitions between females; therefore, body size seems to be more important for competitions in males than in females. This is consistent with the results of Scott \& Traniello (1990), which showed that male Nicrophorus orbicollis that successfully won a carcass were larger than the rest of the population, but there was no difference in the body size of females that won a carcass compared with those that did not. Body size may be more important for males than for females in competing for carcasses because in burying beetles, females mate multiple times (Eggert, 1992) and use sperm from previous matings to fertilize some of their eggs (Müller \& Eggert, 1989), which results in $\sim 15 \%$ of the offspring being sired by non-resident males (Müller et al., 2007). Therefore, winning competitive interactions may be more important for males because they can achieve a much greater fitness if they are the dominant male on the carcass. Competitions may be less important for female fitness because they are able to produce offspring alone on a carcass with stored sperm, by finding a male on a carcass and producing offspring

Table 2. Reproduction experiment analysis table for final brood size, total offspring mass and mean offspring mass

\begin{tabular}{lllrr}
\hline Response variable & Source & Numerator d.f./Denominator d.f. & $F$-value & $P$-value \\
\hline Final brood size & Carcass size & $1 / 91$ & 21.41 & $<0.0001^{*}$ \\
& Male size & $1 / 91$ & 0.33 & 0.56 \\
& Female size & $1 / 91$ & 3.52 & 0.06 \\
Mean offspring mass (g) & Carcass size & $1 / 91$ & 29.86 & 0.95 \\
& Male size & $1 / 91$ & 4.14 & $0.0001^{*}$ \\
Total offspring mass (g) & Female size & $1 / 91$ & 58.24 & $0.045^{*}$ \\
& Carcass size & $1 / 91$ & 0.02 & $0.0001^{*}$ \\
& Male size & $1 / 91$ & 1.5 & 0.89 \\
\hline
\end{tabular}

*Significant values. 

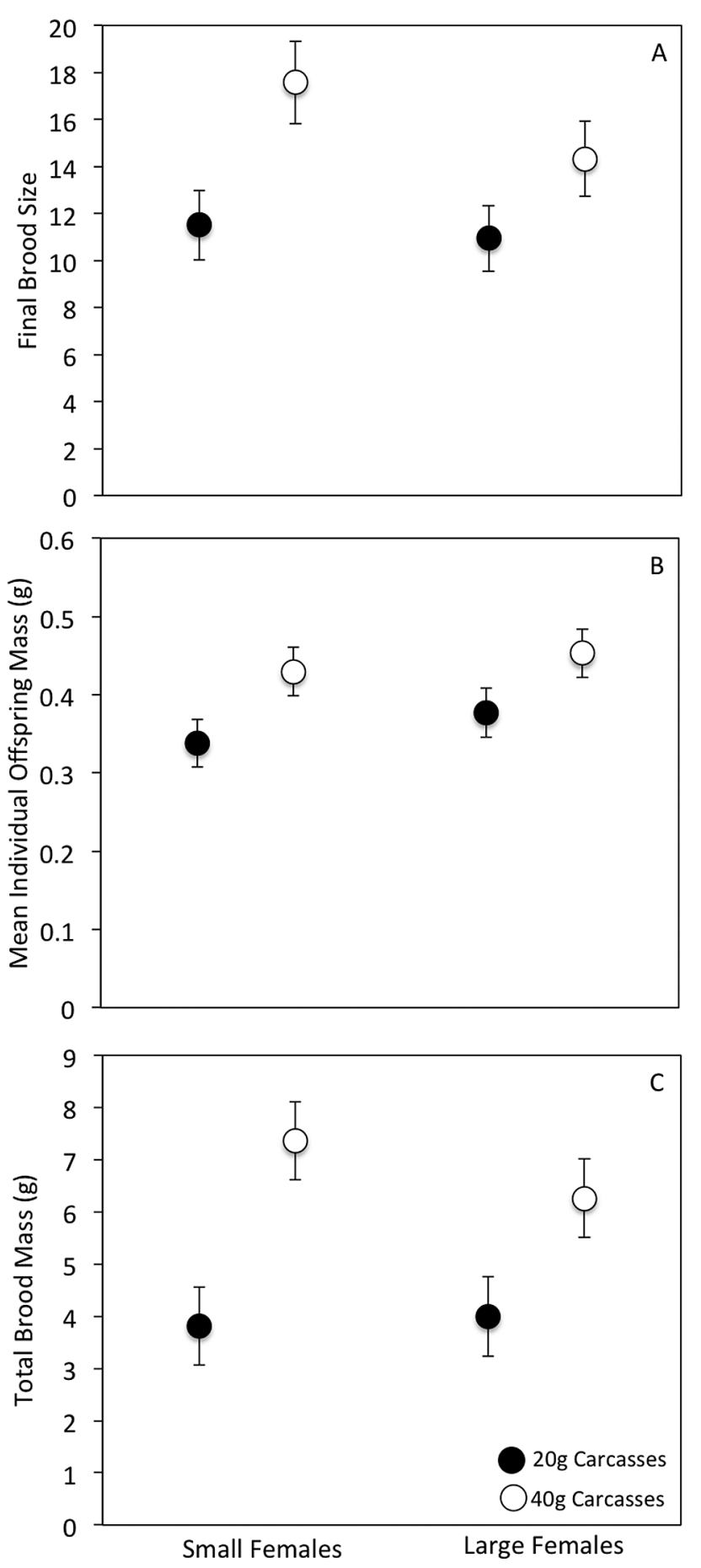

Figure 2. Mean ( $\pm 95 \%$ confidence interval $)$ final brood size (A), individual offspring mass (B) and total brood mass (C) produced by small and large females on both carcass sizes.

biparentally (Eggert \& Müller, 1997) or by parasitizing another female's brood (Trumbo, 1994).

Nicrophorus marginatus is a facultatively biparental species, and therefore we would expect that the body size of both parents would affect offspring size. However, we found that female, but not male, body size had a significant effect on this trait. The lack of an effect of male body size on both the number of offspring produced and the size of offspring might be attributable to their relatively minor role in parental care. Research on other burying beetle species has shown that females are more involved in direct care of offspring (Parker et al., 2015; Smiseth et al., 2005) and suggests that males remain with the brood to provide care if the female dies before the larvae are independent (Parker et al., 2015). In support of this, handicapping and mate removal experiments have shown that males increase their effort when their partner is handicapped or removed, but females generally do not respond (Rauter \& Moore, 2004; Smiseth et al., 2005; Suzuki \& Nagano, 2009; Creighton et al., 2015). Additionally, males are less effective parents when they care for offspring uniparentally (Smith, Creighton \& Belk, 2015). Therefore, male body size might not affect reproductive output because males are less actively involved in caring for offspring than females.

Both large and small females had larger broods on $40 \mathrm{~g}$ carcasses compared with $20 \mathrm{~g}$ carcasses, but large females produced significantly larger and slightly fewer offspring in their broods. Large female insects commonly produce larger eggs that then hatch into larger offspring (e.g. Steiger, 2013; Kojima 2015). Steiger (2013) found that Nicrophorus vespilloides offspring tend to be similar in size to their mothers through transgenerational effects, which could also affect offspring size in $N$. marginatus. However, the largest effect on offspring size is carcass size, so it is possible that larger offspring are simply the result of more food resources from the carcass. However, it is unclear from our results whether the increase in offspring size is attributable to transgenerational effects of maternal size, additional resources from the larger carcass, or an interaction between those two factors.

Although we found that both large and small female $N$. marginatus produce more and larger offspring on larger carcasses, Hopwood et al. (2016) found that in $N$. vespilloides, large beetles had a reproductive advantage over small beetles on large carcasses, but small beetles had a reproductive advantage over large beetles on small carcasses. The opposing results of the two studies might be attributable to differences in the body sizes of these species compared with their competitors. In comparison with other burying beetle species that share the same habitat, $N$. vespilloides are small and $N$. marginatus large (Scott, 1998). Different species of burying beetles are assumed to be able to coexist through resource partitioning according to body size (Scott, 1998; Ikeda et al., 2006), but there is overlap in the sizes of carcasses that different species will use (Scott, 1998; Myers, 2014). Given that large beetles typically win in competitions for carcasses (Otronen, 1988; Safryn \& Scott, 2000; Lee et al., 2014), 
Table 3. Starvation resistance analysis table for days to death

\begin{tabular}{|c|c|c|c|c|}
\hline Response variable & Source & Numerator d.f./Denominator d.f. & $z$-value & $P$-Value \\
\hline \multirow[t]{3}{*}{ Days to death } & Pronotum width & $1 / 50$ & 1.29 & $<0.0001^{*}$ \\
\hline & Sex & $1 / 50$ & 5.06 & 0.1967 \\
\hline & Pronotum width $\times$ sex & $2 / 50$ & 1.37 & 0.1700 \\
\hline
\end{tabular}

*Significant value.

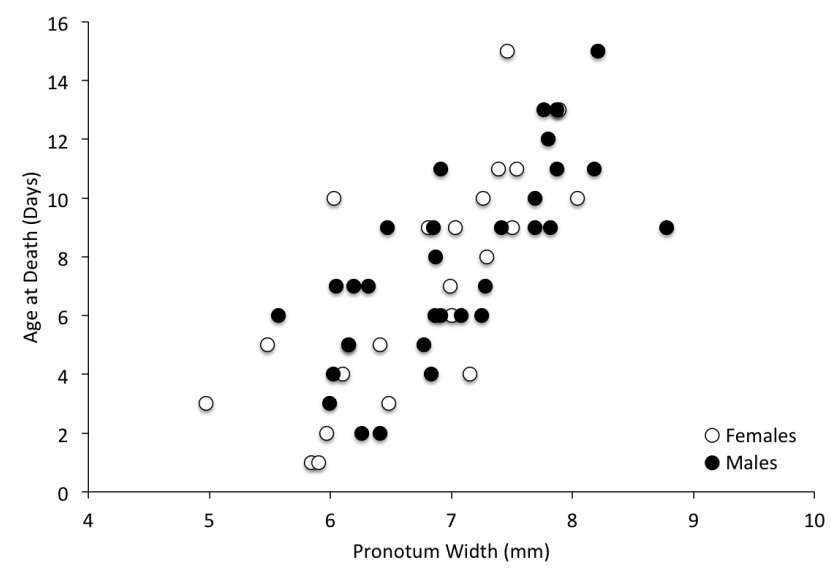

Figure 3. Age at death (in days) according to pronotum width for both sexes.

they could exclude small beetles from the upper end of their carcass range, making small beetles more specialized in their carcass size use. Therefore, a broad range of carcass sizes may be in the natural history profile of $N$. marginatus, but $\operatorname{not} N$. vespilloides, which in turn could cause the differences in the reproductive output between these two species seen on large and small carcasses.

In the present study, larger beetles of both sexes lived longer after eclosion without food than small beetles. This is consistent with the results of a similar experiment done on $N$. orbicollis (Trumbo \& Xhihani, 2015). Larger beetles may be able to survive without food because they have higher fat reserves. In other species of insects, fat content is positively correlated with body size (e.g. Strohm, 2000; O'Neill, Delphia \& O'Neill, 2014), which may allow large individuals to survive without food for longer than small individuals. Although burying beetles can feed on a number of different types of carrion, carcasses are nutrient-rich but ephemeral resources (Eggert \& Müller, 1997); therefore, the frequency at which burying beetles might encounter them is likely to be unpredictable. Directly after eclosion, larger beetles are able to withstand starvation for longer periods of time before finding a carcass, which makes them more likely to survive when environmental conditions are unfavourable.

For both males and females, the advantage of body size in competitions, reproductive output and starvation resistance might be context dependent (Eggert \& Müller, 1997), because population sizes and carcass availabilities are likely to fluctuate both within and between seasons (Scott, 1998; Smith et al., 2000). Insect population sizes tend to fluctuate with their available resources (Dempster \& Pollard, 1981), and burying beetles are no exception. Population densities of Nicrophorus investigator fluctuate yearly (Smith et al., 2000), and changes correspond to small rodent biomass in the previous year (Smith \& Merrick, 2001). A broad range of body sizes exists in natural populations of burying beetles (e.g. Creighton 2005), and the context-dependent importance of body size could maintain these body size ranges. In dense populations, $N$. vespilloides that won access to carcasses were larger on average than individuals that were captured in pitfall traps (Otronen, 1988), but in low-density populations of $N$. orbicollis there were no differences in body size between breeding and non-breeding beetles (Trumbo, 1990). Additionally, $N$. orbicollis parents adjust brood size according to population density and raise fewer, larger offspring when competition is high (Creighton, 2005). However, when population density is low, parents produce more small offspring (Creighton, 2005), which is assumed to be because body size is less important when competition for carcasses is low. Larger offspring produced by larger females might have an advantage only when competition for carcasses is high.

The results of these experiments show a range of responses for the effect of body size on fitness. Body size is more important for males in competitions for carcasses, more important for females in reproductive output, and equally important for males and females in starvation resistance. Therefore, looking at the importance of body size in only one sex or in relationship to only one fitness parameter might not be sufficient to understand the complex interactions that lead to the evolution of this trait.

\section{ACKNOWLEDGEMENTS}

This research was funded by a graduate research grant from the Charles Redd Center. The authors would like to thank the numerous Belk Laboratory 
undergraduate research assistants from 2014 to 2016 for their contributions to this project. We would also like to thank the three reviewers for this manuscript, whose comments made a significant impact on the final version of this paper.

\section{REFERENCES}

Altwegg R, Schaub M, Roulin A. 2007. Age-specific fitness components and their temporal variation in the barn owl. The American Naturalist 169: 47-61.

Amarillo-Suárez AR, Stillwell RC, Fox CW. 2011. Natural selection on body size is mediated by multiple interacting factors: a comparison of beetle populations varying naturally and experimentally in body size. Ecology and Evolution 1: 1-14.

Badyaev AV, Hill GE, Beck ML, Dervan AA, Duckworth RA, McGraw KJ, Nolan PM, Whittingham LA. 2002. Sex-biased hatching order and adaptive population divergence in a passerine bird. Science 295: 316-318.

Blanckenhorn WU. 2000. The evolution of body size: what keeps organisms small? The Quarterly Review of Biology 75: 385-407.

Blanckenhorn WU. 2005. Behavioral causes and consequences of sexual size dimorphism. Ethology 111: 977-1016.

Cleasby IR, Nakagawa S, Gillespie DOS, Burke T. 2010. The influence of sex and body size on nestling survival and recruitment in the house sparrow. Biological Journal of the Linnean Society 101: 680-688.

Clutton-Brock TH. 1983. Selection in relation to sex. In: Bendall BJ, ed. Evolution from molecules to men. Cambridge: Cambridge University Press, 457-481.

Clutton-Brock TH. 1988. Reproductive success: studies of individual variation in contrasting breeding systems. Chicago: The University of Chicago Press.

Creighton JC. 2005. Population density, body size, and phenotypic plasticity of brood size in a burying beetle. Behavioral Ecology 16: 1031-1036.

Creighton JC, Smith AN, Komendat A, Belk MC. 2015. Dynamics of biparental care in a burying beetle: experimental handicapping results in partner compensation. Behavioral Ecology and Sociobiology 69: 265-271.

Dempster JP, Pollard E. 1981. Fluctuations in resource availability and insect populations. Oecologia 50: 412-416.

Eggert AK. 1992. Alternative male mate-finding tactics in burying beetles. Behavioral Ecology 3: 243-254.

Eggert AK, Müller JK. 1997. Biparental care and social evolution in burying beetles: lessons from the larder. In: Choe JC, Crespi BJ, eds. The evolution of social behavior in insects and arachnids. Cambridge: Cambridge University Press, 216-236.

Eggert AK, Sakaluk SK. 2000. Benefits of communal breeding in burying beetles: a field experiment. Ecological Entomology 25: 262-266.

Emlen ST, Oring LW. 1977. Ecology, sexual selection, and the evolution of mating systems. Science 197: 215-223.
Fairbairn DJ, Blanckenhorn WU, Székely T. 2007. Sex, size and gender roles: evolutionary studies of sexual size dimorphism. Oxford: Oxford University Press.

Harrison XA. 2014. Using observation-level random effects to model overdispersion in count data in ecology and evolution. PeerJ 2: e616.

Harrison XA. 2015. A comparison of observation-level random effect and Beta-Binomial models for modelling overdispersion in Binomial data in ecology \& evolution. PeerJ 3: e1114.

Hopwood PE, Moore AJ, Tregenza T, Royle NJ. 2016. Niche variation and the maintenance of variation in body size in a burying beetle. Ecological Entomology 41: 96-104.

Hsu CH, Soong K. 2017. Mechanisms causing size differences of the land hermit crab Coenobita rugosus among eco-islands in Southern Taiwan. PLoS ONE 12: e0174319.

Husby A, Saether BE, Jensen H, Ringsby TH. 2006. Causes and consequences of adaptive seasonal sex ratio variation in house sparrows. The Journal of Animal Ecology 75: 1128-1139.

Ikeda H, Kubota K, Kagaya T, Abe T. 2006. Niche differentiation of burying beetles (Coleoptera: Silphidae: Nicrophorinae) in carcass use in relation to body size: estimation from stable isotope analysis. Applied Entomology and Zoology 41: 561-564.

Kojima W. 2015. Variation in body size in the giant rhinoceros beetle Trypoxylus dichotomus is mediated by maternal effects on egg size. Ecological Entomology 40: 420-427.

Korner-Nievergelt F, Roth T, Von Felten S, Guélat J, Almasi B, Korner-Nievergelt P. 2015. Bayesian data analysis in ecology using linear models with R, BUGS, and Stan. London: Academic Press.

Lee VE, Head ML, Carter MJ, Royle NJ. 2014. Effects of age and experience on contest behavior in the burying beetle, Nicrophorus vespilloides. Behavioral Ecology 25: 172-179.

Merrick MJ, Smith RJ. 2004. Temperature regulation in burying beetles (Nicrophorus spp.: Coleoptera: Silphidae): effects of body size, morphology and environmental temperature. Journal of Experimental Biology 207: 723-733.

Müller JK, Braunisch V, Hwang W, Eggert AK. 2007. Alternative tactics and individual reproductive success in natural associations of the burying beetle, Nicrophorus vespilloides. Behavioral Ecology 18: 196-203.

Müller JK, Eggert AK. 1989. Paternity assurance by "helpful" males: adaptations to sperm competition in burying beetles. Behavioral Ecology and Sociobiology 24: 245-249.

Myers PJ. 2014. Variation in resource utilization and cost of reproduction for two burying beetle species. Unpublished M.S. Thesis, Brigham Young University.

O’Neill KM, Delphia CM, O’Neill RP. 2014. Oocyte size, egg index, and body lipid content in relation to body size in the solitary bee Megachile rotundata. PeerJ 2: e314.

Otronen M. 1988. The effect of body size on the outcome of fights in burying beetles (Nicrophorus). Annales Zoologici Fennici 25: 191-201.

Parker DJ, Cunningham CB, Walling CA, Stamper CE, Head ML, Roy-Zokan EM, McKinney EC, Ritchie MG, Moore AJ. 2015. Transcriptomes of parents identify 
parenting strategies and sexual conflict in a subsocial beetle. Nature Communications 6: 8449.

Peck SB, Kaulbars MM. 1987. A synopsis of the distribution and bionomics of the carrion beetles (Coleoptera: Silphidae) of the conterminous United States. Proceedings of the Entomological Society of Ontario 118: 47-81.

Pilakouta N, Richardson J, Smiseth PT. 2015. Statedependent cooperation in burying beetles: parents adjust their contribution towards care based on both their own and their partner's size. Journal of Evolutionary Biology 28: 1965-1974.

R Core Team. 2013. $R$ : a language and environment for statistical computing. Vienna, Austria: R Foundation for Statistical Computing.

Råberg L, Stjernman M, Nilsson JA. 2005. Sex and environmental sensitivity in blue tit nestlings. Oecologia 145: 496-503.

Rauter CM, Moore AJ. 2004. Time constraints and trade-offs among parental care behaviours: effects of brood size, sex and loss of mate. Animal Behaviour 68: 695-702.

Rauter CM, McGuire MJ, Gwartney MM, Space JE. 2010. Effect of population density and female body size on number and size of offspring in a species with size-dependent contests over resources. Ethology 116: 120-128.

Roff DA. 1992. The evolution of life histories. New York: Chapman \& Hall.

Safryn SA, Scott MP. 2000. Sizing up the competition: do burying beetles weigh or measure their opponents? Journal of Insect Behavior 13: 291-297.

Scott MP. 1998. The ecology and behavior of burying beetles. Annual Review of Entomology 43: 595-618.

Scott MP, Traniello JFA. 1990. Behavioural and ecological correlates of male and female parental care and reproductive success in burying beetles (Nicrophorus spp.). Animal Behaviour 39: 274-283.

Smiseth PT, Dawson C, Varley E, Moore AJ. 2005. How do caring parents respond to mate loss? Differential response by males and females. Animal Behaviour 69: 551-559.

Smith AN, Belk MC, Creighton JC. 2014. Residency time as an indicator of reproductive restraint in male burying beetles. PLoS ONE 9: e109165.

Smith AN, Creighton JC, Belk MC. 2015. Differences in patterns of reproductive allocation between the sexes in Nicrophorus orbicollis. PLoS ONE 10: e0143762.

Smith RJ. 2002. Effect of larval body size on overwinter survival and emerging adult size in the burying beetle, Nicrophorus investigator. Canadian Journal of Zoology 80: 1588-1593.

Smith RJ, Hines A, Richmond S, Merrick M, Drew A, Fargo R. 2000. Altitudinal variation in body size and population density of Nicrophorus investigator (Coleoptera: Silphidae). Environmental Entomology 29: 290-298.

Smith RJ, Merrick MJ. 2001. Resource availability and population dynamics of Nicrophorus investigator, an obligate carrion breeder. Ecological Entomology 26: 173-180.

Steiger S. 2013. Bigger mothers are better mothers: disentangling size-related prenatal and postnatal maternal effects. Proceedings of the Royal Society B: Biological Sciences 280: 20131225.

Strohm E. 2000. Factors affecting body size and fat content in a digger wasp. Oecologia 123: 184-191.

Suzuki S, Nagano M. 2009. To compensate or not? Caring parents respond differentially to mate removal and mate handicapping in the burying beetle, Nicrophorus quadripunctatus. Ethology 115: 1-6.

Trumbo ST. 1990. Reproductive success, phenology and biogeography of burying beetles (Silphidae: Nicrophorus). American Midland Naturalist 124: 1-11.

Trumbo ST. 1994. Interspecific competition, brood parasitism, and the evolution of biparental cooperation in burying beetles. Oikos 69: 241-249.

Trumbo ST, Xhihani E. 2015. Mass-size relationships, starvation and recovery in an engorging feeder. Physiological Entomology 40: 257-263. 